\title{
Growth and Characterization of Vanadate Laser Crystals
}

\author{
H.H. YU, H.J. ZHANG AND J.Y. WANG* \\ State Key Laboratory of Crystal Materials and Institute of Crystal Materials, Shandong University \\ 250100 Jinan, China \begin{abstract}
been grown and commercialized in recent decades. In this paper, the growth and characterization of a series of neodymium doped vanadate crystals have been reviewed, including $\mathrm{Nd}: \mathrm{YVO}_{4}, \mathrm{Nd}: \mathrm{GdVO}_{4}$, and $\mathrm{Nd}_{\mathrm{LuVO}}$. The excellent thermal-mechanical and laser property make them to be used in many respects.
\end{abstract} \\ Based on the invention and widely application of the Czochralski pulling method, vanadate crystals have
}

DOI: 10.12693/APhysPolA.124.301

PACS: $81.10 . \mathrm{Fq}$, 42.55.Px

\section{Introduction}

Since the invention of the Czochralski $(\mathrm{Cz})$ pulling method in 1916 [1], this technology has been well developed and applied as an important tool for exploration and investigation of many new and novel crystals. With the development of lasers, investigation on the growth of laser crystals, especially for those which can be grown with the $\mathrm{Cz}$ method, has attracted wide attention. Neodymium (Nd) doped garnet and vanadate crystals are the best examples for the application of $\mathrm{Cz}$ method. Owing to the development of laser-diode lasers, the neodymium vanadate crystals have become an important series gain materials in the low and even moderate power lasers.

$\mathrm{Nd}: \mathrm{YVO}_{4}$ is the most famous one. Nowadays, its quality has been highly improved and its growth cycle has been reduced using the well known Cz method. This crystal has been commercial and widely adopted in laser processing, generation of visible lasers, etc. Replacing $\mathrm{Y}$ ions by Gd or Lu ions, another vanadate crystal Nd:GdVO $\mathrm{Nd}: \mathrm{LuVO}_{4}$ would be grown. Compared with $\mathrm{Nd} \mathrm{YVO}_{4}$, $\mathrm{Nd}: \mathrm{GdVO}_{4}$ has the highest thermal conductivity and $\mathrm{Nd}: \mathrm{LuVO}_{4}$ possesses the largest emission cross-section among them. In this paper, we review the growth and characterization of a series of vanadate crystals including $\mathrm{Nd}: \mathrm{YVO}_{4}, \mathrm{Nd}: \mathrm{GdVO}_{4}$ and $\mathrm{Nd}: \mathrm{LuVO}_{4}$.

\section{The growth and property of vanadate crystals}

\section{1. $\mathrm{Nd}: \mathrm{YVO}_{4}$ crystals}

The compound of $\mathrm{YVO}_{4}$ material is not chemically existing in nature. In 1928, Goldschmidt and Haralden synthesized this compound firstly [2]. From 1960s, this crystal has been heavily investigated and grown by various flux, zone melting, hydrothermal methods, etc. But the size and quality of the crystal could not meet the need of laser applications. Until 1966, Rubin and Van

\footnotetext{
*corresponding author; e-mail: jywang@sdu.edu.cn
}

Uitert have grown high-quality $\mathrm{YVO}_{4}$ crystal with the Czochralski method [3], which opened the door to commercialization of this crystal. In 1987, Fields et al. first reported the laser-diode pump [4] Nd:YVO 4 laser performance, then this crystal has attracted increasing attention as a gain material for all solid-state lasers.

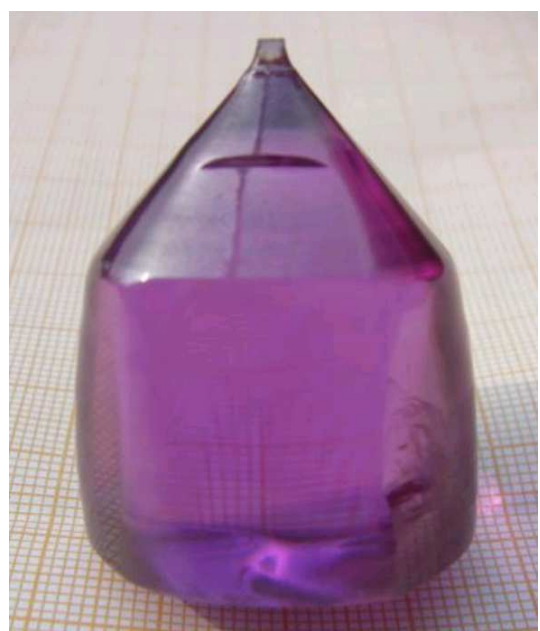

Fig. 1. Photo of as-grown $\mathrm{Nd}: \mathrm{YVO}_{4}$ crystal with doping concentration of 1 at. $\%$.

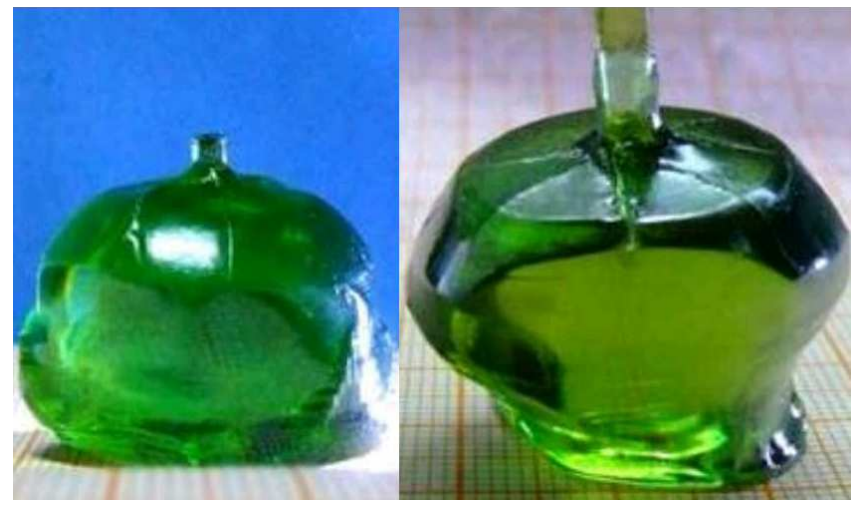

Fig. 2. Photos of Nd:Cr:YVO ${ }_{4}$ crystals with the doping concentration of 0.79 at.\% $\mathrm{Nd}$ and 1.40 at.\% $\mathrm{Cr}$. 
A Nd: $\mathrm{YVO}_{4}$ crystal grown by the Czochralski method is shown in Fig. 1. Compared with the early grown vanadate crystal, the $\mathrm{Nd}: \mathrm{YVO}_{4}$ crystal of Fig. 1 has an excellent quality (no scatter pellets can be observed under $5 \mathrm{~mW}$ He-Ne laser). This crystal is tetragonal with space phase of $D_{4 h}^{19}-I 4_{1} a m d$. Their properties are shown in Table [5]. It can be found that the thermal conductivity of $\mathrm{Nd}: \mathrm{YVO}_{4}$ are much small compared with the Nd:YAG crystal. However, its large absorption and emission cross-section and wide spectra determine its important applications in low and even moderate lasers. Due to the high melting points, $\mathrm{Nd}: \mathrm{YVO}_{4}$ crystal should be grown in oxygen free atmosphere. There were four kinds of defects which would appear in the vanadate crystal: color centers, inclusions, substructure, and uneven distri- bution of $\mathrm{Nd}^{3+}$ concentration [6]. Therefore, the annealing and suitable controlled growing technology are necessary. The doping maximum concentration of 3.2 at.\% has been reported, however, the concentration quenching became evident when the $\mathrm{Nd}^{3+}$ doping concentration is larger than 2 at.\% [7]. The effective segregation coefficient of $\mathrm{Nd}^{3+}$ ions was measured to be 0.63 [8]. Generally, the concentrations of the $\mathrm{Nd}^{3+}$ ions in the shoulder or diameter part are higher than the tail part. Up to now, the maximum of over than $110 \mathrm{~W}$ continuous-wave and mode-locked $\mathrm{Nd}: \mathrm{YVO}_{4}$ laser has been achieved $[9,10]$. Besides the laser performance, $\mathrm{Nd}: \mathrm{YVO}_{4}$ is also a self-Raman laser crystal and the output power of $7.9 \mathrm{~W}$ yellow laser has been achieved with the slope efficiency of $43 \%$ [11].

Characterization of the neodymium doped vanadate crystals.

TABLE

\begin{tabular}{|c|c|c|c|}
\hline & $\mathrm{Nd}: \mathrm{YVO}_{4}$ & $\mathrm{Nd}: \mathrm{GdVO}_{4}$ & $\mathrm{Nd}: \mathrm{LuVO}_{4}$ \\
\hline cell parameters & $\begin{array}{l}a=b=0.7118 \mathrm{~nm}, \\
c=0.6293 \mathrm{~nm}\end{array}$ & $\begin{array}{l}a=b=0.7211 \mathrm{~nm}, \\
c=0.6350 \mathrm{~nm}\end{array}$ & $\begin{array}{l}a=b=0.70243 \mathrm{~nm} \\
c=0.62316 \mathrm{~nm}\end{array}$ \\
\hline melting point & $1810^{\circ} \mathrm{C}$ & $1800^{\circ} \mathrm{C}$ & $1800^{\circ} \mathrm{C}$ \\
\hline Moh's hardness & $4.6-5$ & & \\
\hline density & $4.22 \mathrm{~g} / \mathrm{cm}^{3}$ & $5.48 \mathrm{~g} / \mathrm{cm}^{3}$ & $6.233 \mathrm{~g} / \mathrm{cm}^{3}$ \\
\hline $\begin{array}{l}\text { thermal-optical coefficient } \\
\mathrm{d} n_{\mathrm{\circ}} / \mathrm{d} T \\
\mathrm{~d} n_{\mathrm{e}} / \mathrm{d} T\end{array}$ & $\begin{array}{l}8.5 \times 10^{-6} /{ }^{\circ} \mathrm{C} \\
3.0 \times 10^{-6} /{ }^{\circ} \mathrm{C}\end{array}$ & $4.7 \times 10^{-6} /{ }^{\circ} \mathrm{C}$ & \\
\hline $\begin{array}{l}\text { thermal conductivity } \\
a \text {-axis } \\
c \text {-axis }\end{array}$ & $\begin{array}{l}5.1 \mathrm{~W} / \mathrm{mK} \\
5.23 \mathrm{~W} / \mathrm{mK}\end{array}$ & $\begin{array}{l}10.1 \mathrm{~W} / \mathrm{mK} \\
11.4 \mathrm{~W} / \mathrm{mK}\end{array}$ & $\begin{array}{l}7.96 \mathrm{~W} / \mathrm{mK} \\
9.77 \mathrm{~W} / \mathrm{mK}\end{array}$ \\
\hline absorption peak & $808.6 \mathrm{~nm}$ & $808.4 \mathrm{~nm}$ & $807 \mathrm{~nm}$ \\
\hline $\begin{array}{l}\text { width of absorption peak } \\
\text { (full width at half maximum) } \\
\text { at } 808 \mathrm{~nm}\end{array}$ & $2 \mathrm{~nm}(1.0$ at. $\% \mathrm{Nd})$ & $1.6 \mathrm{~nm}(1.2$ at.\% Nd) & $1.5 \mathrm{~nm}(0.36$ at.\% $\mathrm{Nd})$ \\
\hline absorption cross-section & $5.7 \times 10^{-19} \mathrm{~cm}^{2}$ & $5.2 \times 10^{-19} \mathrm{~cm}^{2}$ & $6.9 \times 10^{-19} \mathrm{~cm}^{2}$ \\
\hline emission peak & $1064 \mathrm{~nm}$ & $1063 \mathrm{~nm}$ & $1066 \mathrm{~nm}$ \\
\hline $\begin{array}{l}\text { width of emission peak } \\
\text { (full width at half maximum) } \\
\text { at } 1064 \mathrm{~nm}\end{array}$ & $1.5 \mathrm{~nm}(\approx 1 \% \mathrm{Nd}$ concentration $)$ & $1.2 \mathrm{~nm}(1.2$ at. $\% \mathrm{Nd})$ & $2.1 \mathrm{~nm}(1$ at. $\% \mathrm{Nd})$ \\
\hline emission cross-section & $12 \times 10^{-19} \mathrm{~cm}^{2}$ & $7.6 \times 10^{-19} \mathrm{~cm}^{2}$ & $14.6 \times 10^{-19} \mathrm{~cm}^{2}$ \\
\hline fluorescence lifetime & $76 \mu \mathrm{s}$ & $90 \mu \mathrm{s}$ & $82 \mu \mathrm{s}$ \\
\hline Sellmeier equation & $\begin{array}{l}n_{\mathrm{o}}^{2}=3.77834+0.069736 \\
\quad /\left(\lambda^{2}-0.04724\right)-0.01081133 \lambda^{2} \\
n_{\mathrm{e}}^{2}=4.59905+0.110534 \\
\quad /\left(\lambda^{2}-0.04813\right)-0.0122676 \lambda^{2}\end{array}$ & $\begin{array}{l}n_{\mathrm{o}}^{2}=3.8714+0.0604 \\
\quad /\left(\lambda^{2}-0.06119\right)-0.03961 \lambda^{2} \\
n_{\mathrm{e}}^{2}=4.7331+0.1054 \\
\quad /\left(\lambda^{2}-0.06112\right)-0.02409 \lambda^{2}\end{array}$ & \\
\hline
\end{tabular}

Nowadays, we have developed the self- $Q$-switched $\mathrm{Nd}: \mathrm{Cr}: \mathrm{YVO}_{4}$ laser crystals as shown in Fig. 2 based on our previous investigation of $\mathrm{Nd}: \mathrm{YVO}_{4}[12,13]$ with the size of $\oslash 32 \times 20 \mathrm{~mm}^{2}$. In this crystal, the $\mathrm{V}^{5+}$ ions are partly substituted by $\mathrm{Cr}^{5+}$ which has saturable absorbing property when they are localized in the tetragonal coordination. Based on the emission property of $\mathrm{Nd}$ ions and saturable absorbing property of $\mathrm{Cr}$ ions, this crystal can be used as a self-modulated pulsed laser gain material.

\section{2. $\mathrm{Nd}: \mathrm{GdVO}_{4}$ crystals}

From 1990s, the $\mathrm{Nd}: \mathrm{GdVO}_{4}$ crystal with small size has been investigated. Until 1992, the large size Nd:GdVO crystal was firstly grown with the Czochralski method by 
Zagumennyi et al. [14] and used as a gain material for the generation of lasers. In 1994, Jensen et al. investigated the spectral and laser properties of this crystal systematically [15]. In 1995, Studenikin et al. reported its thermal properties and refractive index [16]. From 1996, we started the investigation of growth and properties of this crystal. In 2002, we reviewed the laser properties of this crystal including its fundamental laser performance and applications in second harmonic generation [8]. Since then, this crystal has been widely studied and used in moderate and even high power lasers. Up to now, over $100 \mathrm{~W} \mathrm{Nd}: \mathrm{GdVO}_{4}$ lasers have been achieved with the efficiency of $40 \%$ [17]. The shortest $\mathrm{Nd}: \mathrm{GdVO}_{4}$ laser pulse is $2.8 \mathrm{ps}$ [18]. In the application of self-Raman lasers, the continuous-wave yellow laser of $5.3 \mathrm{~W}$ was achieved with $\mathrm{Nd}: \mathrm{GdVO}_{4}$ as the gain and Raman material [19] where the optical efficiency is $21 \%$.

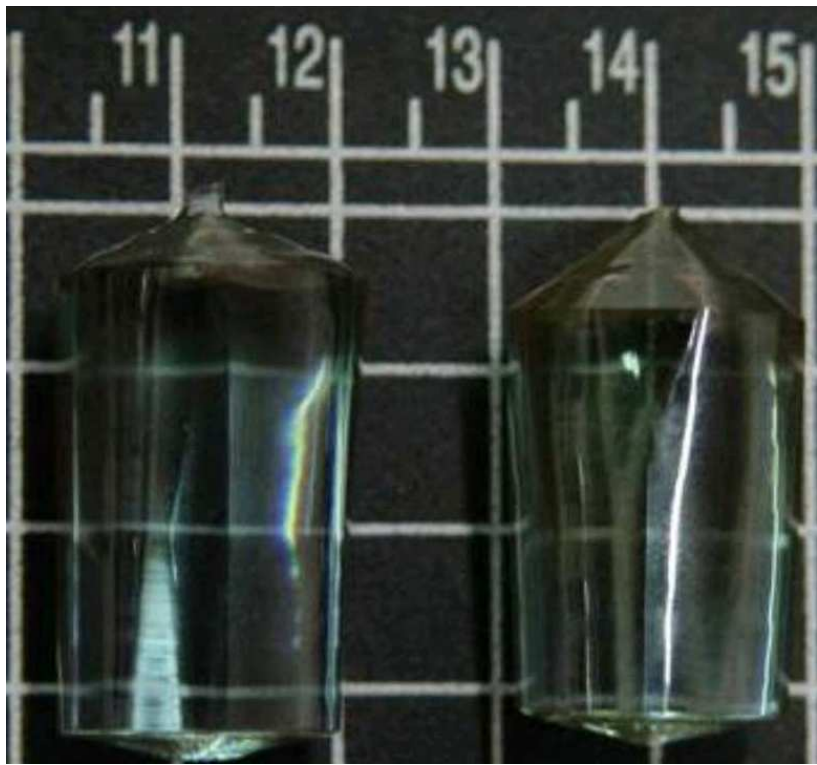

Fig. 3. Photos of as-grown $\mathrm{Nd}: \mathrm{GdVO}_{4}$ crystals with the doping concentration of 1.56 at.\%.

The basic properties of $\mathrm{Nd}: \mathrm{GdVO}_{4}$ crystal is also shown in Table and the as grown crystal is presented in Fig. 3. Compared with $\mathrm{Nd}: \mathrm{YVO}_{4}, \mathrm{Nd}: \mathrm{GdVO}_{4}$ has much higher thermal conductivity which is comparable with Nd:YAG crystals and higher effective segregation coefficient of $\mathrm{Nd}^{3+}$ ions (0.78) [8]. Its emission cross-section is larger than Nd:YAG, therefore, this crystal was considered as a gain medium for the generation of efficient moderate and even high power lasers.

\section{3. $\mathrm{Nd}: \mathrm{LuVO}_{4}$ crystals}

From 1996, Terada et al. have investigated $\mathrm{LuVO}_{4}$ crystals as optical materials [20]. Until 2002, Maunier et al. grew and studied the optical and laser properties of $\mathrm{Nd}: \mathrm{LuVO}_{4}$ [21] with the flux method. In 2003, we reported the growth of large-size $\mathrm{Nd}: \mathrm{LuVO}_{4}$ crystals with the Czochralski method for the first time to our knowledge [22]. The as-grown $\mathrm{Nd}: \mathrm{LuVO}_{4}$ crystals with different doping concentrations (0-3 at.\%) are shown in Fig. 4. The basic properties of the $\mathrm{Nd}: \mathrm{LuVO}_{4}$ crystal is also summarized in Table. Its thermal conductivity is a bit smaller than $\mathrm{Nd}: \mathrm{GdVO}_{4}$ and $\mathrm{Nd}: \mathrm{YAG}$, but much larger than $\mathrm{Nd}: \mathrm{YVO}_{4}$. The higher effective segregation coefficient of $\mathrm{Nd}^{3+}$ ions in $\mathrm{Nd}: \mathrm{LuVO}_{4}$ crystal is 0.91 . The emission cross-section of $\mathrm{Nd}: \mathrm{LuVO}_{4}$ is about twice of that for $\mathrm{Nd}: \mathrm{GdVO}_{4}$, which indicates that the $\mathrm{Nd}: \mathrm{LuVO}_{4}$ should be an excellent laser material for the generation of high efficient lasers at about $1.06 \mu \mathrm{m}$. The maximum continuous-wave output power is $17.2 \mathrm{~W}$ [23] and the shortest $Q$-switched pulse is 12 ns and the shortest mode-locked pulse is $7.1 \mathrm{ps}$ [24]. The maximum output power of $3.5 \mathrm{~W}$ yellow laser was achieved with $\mathrm{Nd}: \mathrm{LuVO}_{4}$ as the gain and Raman material [25]. However, this crystal has strong up-conversion at the wavelength of $1.3 \mu \mathrm{m}$, which determines the relative low efficient lasers at this wavelength.

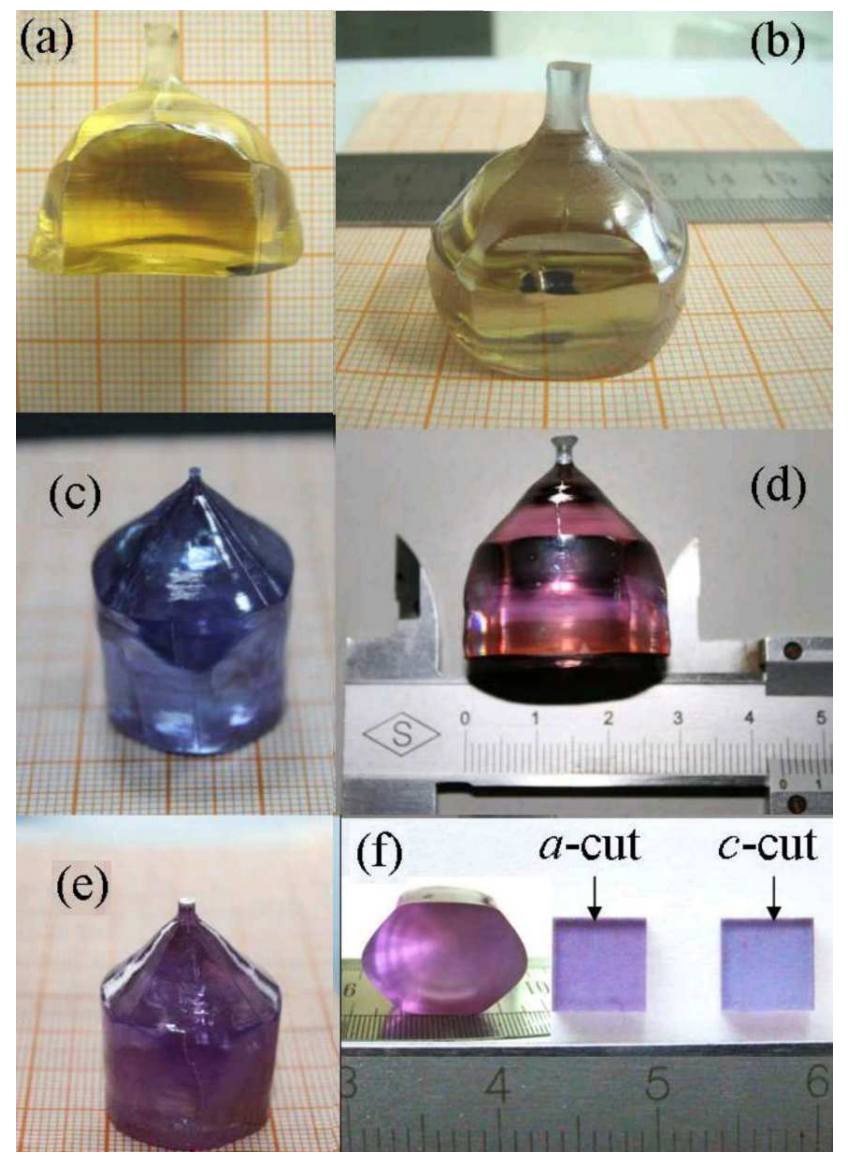

Fig. 4. Nd:LuVO ${ }_{4}$ crystals with doping concentrations from 0 to 3 at. $\%$.

\section{Conclusion}

The neodymium doped vanadate crystals have been widely studied and identified as excellent laser gain materials. As the development of solid-state lasers, it can be 
proposed that these crystals would play more and more important roles. As possible future prospects, the novel vanadate laser crystals with smaller cations such as $\mathrm{Sc}^{3+}$ and larger cations such as $\mathrm{La}^{3+}$ should be paid more attentions, because $\mathrm{Sc}^{3+}$ has the smallest radius which determines the atypical crystal growing property [26], and $\mathrm{La}^{3+}$ has the largest radius which induces the different crystal symmetry [27].

\section{References}

[1] J. Czochralski, Z. Phys. Chem. 92, 219 (1918).

[2] E.B. Roch, J. Phys. Chem. 20, 345 (1933).

[3] J.J. Rubin, L.G. Van Uitert, J. Appl. Phys. 37, 2920 (1966).

[4] R.A. Fields, M. Birnbaum, C.L. Fincher, Appl. Phys. Lett. 51, 1885 (1987).

[5] H.R. Xia, X.L. Meng, M. Guo, L. Zhu, H.J. Zhang, J.Y. Wang, J. Appl. Phys. 88, 5134 (2000).

[6] B.Q. Hu, Y.Z. Zhang, X. Wu, X.L. Chen, J. Cryst. Growth 226, 511 (2001).

[7] Z.P. Wang, X. Sun, X.G. Xu, L.K. Sun, S.J. Sun, X.L. Meng, R.P. Cheng, Z.S. Shao, Chin. J. Quantum Electron. 18, 104 (2000).

[8] H.J. Zhang, J.H. Liu, J.Y. Wang, L. Zhu, Z.S. Shao, X.L. Meng, X.B. Hu, M.H. Jiang, Y.T. Chow, J. Opt. Soc. Am. B 19, 18 (2002).

[9] L. McDonagh, R. Wallenstein, A. Nebel, Opt. Lett 32, 1259 (2007).

[10] P. Shi, D. Li, H. Zhang, Y. Wang, K. Du, Opt. Commun. 229, 349 (2004).

[11] H. Zhu, Y. Duan, G. Zhang, C. Huang, Y. Wei, H. Shen, Y. Zheng, L. Huang, Z. Che, Opt. Express 17, 21544 (2009).

[12] S.A. Zolotovkaya, K V. Yumashev, N.V. Kuleshov, V.N. Matrosov, T.A. Matrosova, M.I. Kupchenko, Appl. Phys. B 86, 667 (2007).

[13] Z.B. Pan, B. Yao, H.H. Yu, H.H. Xu, Z.P. Wang, J.Y. Wang, H.J. Zhang, Opt. Express 30, 2178 (2012).
[14] A.I. Zagumennyi, V.G. Ostroumov, I.A. Shcherbakov, T. Jensen, J.P. Meyen, G. Huber, Sov. J. Quantum Electron. 22, 1071 (1992).

[15] T. Jensen, V.G. Ostroumov, J.P. Meyn, G. Huber, A.I. Zagumennyi, I.A. Shcherbakov, Appl. Phys. B 58, 373 (1994).

[16] P.A. Studenikin, A.I. Zagumennyi, Yu D. Zavartsev, P.A. Popov, I.A. Shcherbakov, Quantum Electron. 25, 1162 (1995).

[17] A. Minassian, B.A. Thompson, G. Smith, M.J. Damzen, IEEE J. Select. Top. Quantum Electron. 11, 621 (2005).

[18] S.J. Holmgren, V. Pasiskevicius, F. Laurell, Opt. Express 13, 5270 (2005).

[19] A.J. Lee, H.M. Pask, D.J. Spence, J.A. Piper, Opt. Lett. 35, 682 (2010).

[20] Y. Terada, K. Shimamura, V.V. Kochrikhin, L.V. Barashov, M.A. Ivanov, T. Fukuda, J. Cryst. Growth 167, 369 (1996).

[21] C. Maunier, J.L. Doualan, R. Moncorge, A. Speghini, M. Bettinelli, E. Cavalli, J. Opt. Soc. Am. B 19, 1794 (2002).

[22] H.J. Zhang, H.K. Kong, S.R. Zhao, J.H. Jiu, J.Y. Wang, Z.P. Wang, L. Gao, C.L. Du, X.B. Hu, X.G. Xu, Z.S. Shao, M.H. Jiang, J. Cryst. Growth 256, 292 (2003).

[23] M. Xu, H. Yu, H. Zhang, Z. Wang, X. Xu, J. Wang, C. Ma, Laser Phys. Lett. 8, 269 (2011).

[24] H. Yu, H. Zhang, Z. Wang, J. Wang, Z. Shao, M. Jiang, X. Zhang, Opt. Express 15, 3206 (2007).

[25] H. Yu, H. Zhang, Z. Wang, J. Wang, Y. Yu, M. Jiang, D. Tang, G. Xie, H. Luo, Opt. Lett. 33, 225 (2008).

[26] H.J. Cong, H.J. Zhang, B. Yao, W.T. Yu, Z.X. Zhao, J.Y. Wang, G.C. Zhang, Cryst. Growth Des. 10, 4389 (2010).

[27] H. Cong, H. Zhang, S. Sun, Y. Yu, W. Yu, H. Yu, J. Zhang, J. Wang, R.I. Boughton, J. Appl. Cryst. 43, 308 (2010). 